\title{
Dynamic Switch Between Two Adhesion Phenotypes in Colorectal Cancer Cells
}

\author{
Yue Geng, Siddarth Chandrasekaran, Sivaprakash Agastin, Jiahe Li, and Michael R. King \\ Department of Biomedical Engineering, Cornell University, Ithaca, NY 14853, USA
}

(Received 21 August 2013; accepted 26 October 2013; published online 14 November 2013)

Associate Editor Pierre Bongrand oversaw the review of this article.

\begin{abstract}
The hematogenous metastatic cascade is mediated by the interaction of cancer cells and the endothelial cell lining of blood vessels. In this work, we examine the colon cancer cell line COLO 205, which grows simultaneously in both adherent and suspended states in culture and can serve as a good model for studying tumor heterogeneity. The two subpopulations of cells have different molecular characteristics despite being from the same parent cell line. We found that the ratio of adherent to suspended cells in culture is maintained at 7:3 (equilibrium ratio). The ratio was maintained even when we separate the two populations and culture them separately. After $8 \mathrm{~h}$ in culture the equilibrium was achieved only from either adherent or suspended population. The adherent cells were found to express less E-selectin binding glycans and demonstrated significantly weaker interaction with E-selectin under flow than the suspended cells. Manipulation of the epithelial-mesenchymal transition (EMT) markers $\beta$-catenin and E-cadherin expression, either by siRNA knockdown of $\beta$-catenin or incubation with E-cadherin antibody-coated microbeads, shifted the ratio of adherent to suspended cells to 9:1. Interestingly, human plasma supplemented media shifted the ratio of adherent to suspended cells in the opposite direction to 1:9, favoring the suspended state. The dynamic COLO 205 population switch presents unique differential phenotypes of their subpopulations and could serve as a good model for studying cell heterogeneity and the EMT process in vitro.
\end{abstract}

Keywords-Cell adhesion, E-selectin, $\beta$-Catenin, E-cadherin, Metastasis.

\section{INTRODUCTION}

Colorectal cancer is one of the most frequent human tumors, which can metastasize to liver, lung, and

Address correspondence to Michael R. King, Department of Biomedical Engineering, Cornell University, Ithaca, NY 14853, USA. Electronic mail: mike.king@cornell.edu

Yue Geng and Siddarth Chandrasekaran contributed equally to this work. peritoneum. Significant intratumoral genetic heterogeneity has been demonstrated in advanced colorectal carcinoma, indicating the importance to re-evaluate the use of genetic markers for prognosis. ${ }^{2}$ Genetic heterogeneity is known to play a key role in determining which cells from the primary tumor ultimately metastasize. The heterogeneity dictated by reduction or loss of E-cadherin that mediates homotypic cell-cell adhesion has been shown to promote the progression of several carcinomas including colorectal cancers. ${ }^{15,16,20,22}$ This reduced cell-cell adhesiveness permits cells to deviate from normal cell growth patterns, resulting in the destruction of histological structures. As an important member of the cadherin family, the cytoplasmic domain of the $\mathrm{Ca}^{2+}$ dependent transmembrane glycoprotein E-cadherin regulates the structural and signaling activities required for adhesion through interactions with $\beta$-catenin, $\alpha$-catenin and plakoglobin $(\gamma$-catenin $) .{ }^{29} \mathrm{Wnt}$ signal mediated tyrosine phosphorylation of $\beta$-catenin has been established as an important regulatory mechanism behind cytoplasmic protein stabilization as the phosphorylated protein has less affinity to both the APC/GSK-3/Axin complex and E-cadherin. ${ }^{6}$ The loss of E-cadherin mediated cell-cell adhesion and phosphorylation of $\beta$-catenin has been shown to play an important role in the metastasis of colorectal cancer. ${ }^{4}$

Metastasis is a complex and highly organized process that involves a series of distinct steps. ${ }^{19}$ The formation of metastases by invasive transformed cells accounts for $90 \%$ of all deaths in cancer patients. ${ }^{31}$ To form secondary tumors, cancer cells must invade the surrounding tissue and enter either the bloodstream or the lymphatic system. Similar to the leukocyte adhesion cascade which is initiated via cell tethering and rolling through selectin mediated interactions, cancer cells displaying selectin ligands are potentially involved in a series of events that eventually lead to metastasis, i.e. the metastatic cascade. ${ }^{9,14,17,21}$ 
Following intravasation, selectins can interact with a variety of $O$-glycosylated ligands and, in turn, mediate the transient adhesion of cells to the endothelium. These receptor-ligand interactions represent the first contact between cancer cells and the endothelial wall, which facilitates tethering and rolling events. ${ }^{10}$ Sialic acids are terminal monosaccharides attached to cell surface glycoconjugates and play important roles in many physiological and pathological processes. ${ }^{11}$ Over a decade ago, researchers found that tumor cells overexpress sialyl Lewis $\mathrm{x}\left(\mathrm{sLe}^{\mathrm{x}}\right)$ or sialyl lewis a $\left(\mathrm{sLe}^{\mathrm{a}}\right)$ on their surface glycoproteins and/or glycosphingolipids in lung, colon, gastric, and pancreatic carcinomas. ${ }^{3} \mathrm{sLe}^{\mathrm{x}}$-bearing human colon adenocarcinoma cell lines including COLO 205 and LS174T have been shown to undergo extensive adhesive interactions with E- and P-selectin under flow conditions. ${ }^{1,12}$ The human colon carcinoma cell line COLO 205 was established from the ascetic fluid of a male patient with poorly differentiated colorectal carcinoma by Semple et $a{ }^{27}$ Interestingly, this cell line has a unique morphological character in that it grows simultaneously in both adherent and suspended states in culture. In this work, we observed that when separated, both suspended and adherent populations of COLO 205 generate their counterpart populations and re-distribute so that the ratio of adherent cells to suspended cells in culture is always 7:3. This is referred to as the "equilibrium ratio" in the rest of the paper. In this study, we further examined the kinetics of this phenomenon and investigated the tumor heterogeneity between the COLO 205 adherent and suspended populations and biochemical factors that modulate this equilibrium ratio.

\section{MATERIALS AND METHODS}

\section{Cell Line and Cell Culture}

The COLO 205 cell line was obtained from ATCC (American Type Culture Collection, Manassas, VA). Gibco ${ }^{\circledR}$ RPMI media (Life Technologies, Grand Island, NY), supplemented with $10 \%$ fetal bovine serum (Life Technologies, Grand Island, NY), $100 \mathrm{IU} / \mathrm{mL}$ penicillin and $10 \mu \mathrm{g} / \mathrm{mL}$ streptomycin (Life Technologies, Grand Island, NY) was used as growth media. Cells were cultured in BD Falcon ${ }^{\mathrm{TM}} 75 \mathrm{~cm}^{2}$ cell culture flasks at $37{ }^{\circ} \mathrm{C}$ in an incubator supplied with $5 \% \mathrm{CO}_{2}$. To collect the adherent COLO 205 cells, enzyme free dissociation buffer (Life Technologies, Grand Island, NY) was added after removing the suspended population. $90 \%$ cell viability was confirmed with trypan blue dye exclusion using a hemocytometer.

\section{Cell Population Assay}

Adherent and suspended populations of COLO 205 cells were separated and deposited in 6-well plates. At time points $0,0.5,1,2,4,6$, and $8 \mathrm{~h}$, cells were collected and counted as described above. In separate experiments, adherent and suspended COLO 205 cells were separated and labeled with CellTracker Green and Orange (Life Technologies, Grand Island, NY), respectively. The adherent green cells were then replated at 0.2 million cells per well in a 12 -well plate and allowed to reach an equilibrium adherent:suspended ratio for $8 \mathrm{~h}$. Likewise, the suspended orange cells were re-plated at the same concentration and equilibrated for $8 \mathrm{~h}$. The suspended and adherent populations for both the green and orange cultures were separated again. Finally, the orange suspended cells were deposited into the wells containing only the green adherent layer. The numbers of orange and green cells in the suspended and adherent layers were counted from $500 \mu \mathrm{L}$ cell solutions of each population using a flow cytometer every $2 \mathrm{~h}$ for $10 \mathrm{~h}$, to assess the rate of phenotype "flip-flop".

\section{Reverse Transcription}

Total RNA from COLO 205 suspended and adherent cells was prepared and purified separately using RNeasy Plus Mini kit (Qiagen). The $40 \mu \mathrm{L}$ reverse transcription reaction system includes $10 \mu \mathrm{g}$ of total RNA, $1 \mu \mathrm{L}$ of M-MuLV Reverse Transcriptase (New England Biolabs), $0.5 \mu \mathrm{L}$ of RNase Inhibitor (New England Biolabs), $1 \mu \mathrm{L}$ of Random Primers (Invitrogen), $2.5 \mu \mathrm{L}$ of dNTP Mix (New England Biolabs) and $4 \mu \mathrm{L}$ of MuLV Reverse Transcriptase reaction buffer (New England Biolabs). The reaction mixture was incubated inside the RT-PCR (Bio-Rad) instrument at $42{ }^{\circ} \mathrm{C}$ for $1 \mathrm{~h}$, followed by an inactivation step at $95^{\circ} \mathrm{C}$ for $10 \mathrm{~min}$.

\section{Real-Time Quantitative PCR ( $q P C R$ )}

$10 \mathrm{ng}$ of cDNA produced by the reverse transcription of total RNA was used in each qPCR reaction. Also included in the $20 \mu \mathrm{L}$ qPCR reaction system were $10 \mu \mathrm{L} \mathrm{iQ}^{\mathrm{TM}}$ SYBR Supermix (Bio-Rad), $1 \mu \mathrm{L}$ of $2 \mu \mathrm{M}$ forward primer and $1 \mu \mathrm{L}$ of $2 \mu \mathrm{M}$ reverse primer and nuclease free water.

\section{Primer for $\beta$-Catenin qPCR (Product Size: $166 \mathrm{bp}$ ) \\ 5'-GAAACGGCTTTCAGTTGAGC-3' (forward) 5'-CTGGCCATATCCACCAGAGT-3' (reverse)}

$$
\begin{aligned}
& \text { Primer for GAPDH qPCR (Product Size: } 170 \mathrm{bp} \text { ) } \\
& \text { 5'-AGAGCACAAGAGGAAGAGAGAGAC-3' } \\
& \text { (forward) }
\end{aligned}
$$


5'-AGCACAGGGTACTTTATTGATGGT-3' (reverse)

qPCR reactions were carried out in 96-well real-time PCR plates (Bio-Rad) using a Bio-Rad MyIQ Realtime PCR detection system. The qPCR reaction included $5 \mathrm{~min}$ at $95{ }^{\circ} \mathrm{C}$ to activate the polymerase and 50 PCR cycles (uncoupling step at $95^{\circ} \mathrm{C}$ for $20 \mathrm{~s}$ followed by annealing step at $59{ }^{\circ} \mathrm{C}$ for $20 \mathrm{~s}$ and elongation step at $72{ }^{\circ} \mathrm{C}$ for $30 \mathrm{~s}$ ), followed by a melting temperature analysis to test for any nonspecific amplification. All the qPCR reactions were performed in triplicate. The expression level of $\beta$-catenin gene in each cell population was normalized to the expression level of the standard gene GAPDH.

\section{siRNA Transfection}

$\beta$-Catenin siRNA was purchased from Applied Biosystems $\left(\right.$ Silencer ${ }^{\circledR}$ pre-designed $\&$ validated siRNA, ID: s436). Lipofectamine ${ }^{\mathrm{TM}}$ RNAiMAX (Invitrogen) reagent was used to transfect the COLO 205 cells with $\beta$-catenin siRNA as described by the manufacturer.

\section{E-cadherin Antibody Coated Bead Incubation}

Protein A coated polystyrene beads $(500 \mu \mathrm{L}, 1 \% \mathrm{w} /$ $\mathrm{v}$, Spherotech, Lake Forest, IL) were first incubated with $2 \mathrm{~mL}$ of $50 \mu \mathrm{g} / \mathrm{mL}$ mouse anti-human E-cadherin monoclonal antibodies (Santa Cruz Biotechnology, Santa Cruz, CA) on ice for $45 \mathrm{~min}$. Conjugated beads were washed once with $1 \mathrm{~mL}$ PBS and then resuspended with $500 \mu \mathrm{L}$ of fresh media. $250 \mu \mathrm{L}$ of beadcontaining media was added to COLO 205 cells cultured in 6-well plates and incubated for $2 \mathrm{~h}$ at $37^{\circ} \mathrm{C}$ before cell counting and mRNA analysis.

\section{Flow Cytometry}

Adherent and suspended populations of COLO 205 cells were separated, washed with $1 \times$ DPBS, and resuspended in $1 \times$ DPBS with $1 \%$ BSA to a final concentration of 20,0000-30,0000 cells in each sample. Antibodies or appropriate isotype controls were added to cell suspensions and incubated over ice for $45 \mathrm{~min}$. Following the incubations, the cells were washed three times with $1 \mathrm{~mL}$ of $1 \times$ DPBS to remove any unbound antibody. Flow cytometry samples were analyzed using an Accuri C6 flow cytometer (Accuri Cytometers Inc., Ann Arbor, Michigan, USA) and plots were created using the FCS Express package.

\section{Proteome Profiler Assay}

Human Phospho-kinase Antibody array kit (R\&D systems) was used to analyze the phosphorylation profiles of several key kinases and their protein substrates in both the adherent and suspended COLO 205 cells. Adherent and suspended cells were separated, washed in ice cold PBS buffer, and pelleted before adding the lysis buffer provided with the array kit. Total protein concentrations were determined by Bradford colorimetric assay (Bio-Rad). The nitrocellulose membranes provided with the kit were processed and developed as per the manufacturer's instructions.

\section{Immunoblotting}

Whole cell lysate from both subpopulations was freshly made using RIPA lysis and extraction buffer. The lysate protein concentrations were measured using Bradford assay (BioRad). SDS-PAGE was performed using $7.5 \%$ polyacrylamide gels and proteins were transferred to a nitrocellulose membrane, incubated with primary antibodies against $\beta$-catenin (Biolegend) and $\beta$-actin (Santa Cruz Biotechnology) overnight at $4{ }^{\circ} \mathrm{C}$. Goat anti-rabbit IgG-HRP (Santa Cruz Biotechnology) and rabbit anti-mouse IgG-HRP (Abcam) were used as secondary antibodies.

\section{Cell Rolling Assay}

Microrenathane tubing with $300 \mu \mathrm{m}$ internal diameter (Braintree Scientific) was cut to a length of $50 \mathrm{~cm}$, functionalized with Protein $\mathrm{G}(10 \mu \mathrm{g} / \mathrm{mL})$ and $\mathrm{Fc}$ chimera E-selectin $(20 \mu \mathrm{g} / \mathrm{mL}, \mathrm{R} \& \mathrm{D})$, and blocked with $5 \%$ BSA or milk (Sigma). Functionalized microtubes were then secured to the stage of an Olympus IX81 motorized inverted microscope (Olympus America, Melville, NY). A CCD camera (model no: KP-M1AN, Hitachi, Tokyo, Japan) and DVD recorder (model no: DVD-1000MD, Sony Electronics) were used to record experiments for offline analysis. Adherent and suspended COLO 205 cells were separated and suspended in flow buffer at $1 \times 10^{6}$ cells $/ \mathrm{mL}$ and perfused through protein coated microtubes using a syringe pump (KDS 230, IITC Life Science, Woodland Hills, CA) at a wall shear stress of $1.0 \mathrm{dyn} / \mathrm{cm}^{2}$.

\section{qPCR Profiling of EMT-Associated Genes}

RNA was extracted from adherent and suspended cells by TRIZOL method. First strand cDNA was synthesized using the Invitrogen first strand cDNA synthesis kit. Qiagen EMT PCR array including qPCR primers for signature genes during EMT was performed in the Biorad iQ qPCR machine to compare gene expression exhibited by the two populations using the $2^{-\Delta C t}$ method. Gene expression was normalized to the housekeeping genes GAPDH and $\beta$-actin. 


\section{Plasma Isolation and Treatment}

Whole peripheral blood was drawn from informed consenting healthy donors by venipuncture into BD Vacutainer tubes. Collected whole blood was centrifuged for $25 \mathrm{~min}$ at $500 \mathrm{rpm}$. The plasma layer on top was carefully removed without disturbing the interface and passed through a sterile $0.2 \mu \mathrm{m}$ filter. $50 \%$ of the isolated plasma supplemented culture media was used to culture COLO 205 cells at $2 \times 10^{5}$ cells/well in 6well plates prior to experiments.

\section{RESULTS}

\section{Separation of Adherent and Suspended Subpopulations Resulted in the Re-establishment of the Equilibrium Ratio}

When cultured in monolayers, COLO 205 cells grow simultaneously in both adherent and suspended states. While the adherent COLO 205 cells grow in small aggregates (2-dimensional islands), the suspended population grows as individual cells. To separate the two populations, suspended cells were collected and plated in a new culture flask while fresh media was added to the original flask containing the adherent population. Cell counting and viability assay were performed using trypan blue dye and a hemocytometer at various time points including $0,0.5,1,2,4,6$, and $8 \mathrm{~h}$. Interestingly, each flask initiated with either all adherent or all suspended cells was observed to re-establish an "equilibrium ratio" of $70 \%$ adherent cells to $30 \%$ suspended cells within $8 \mathrm{~h}$, as shown in Fig. 1. A simple mathematical model was formulated to describe the kinetics for the adherent $(A)$ and suspended $(S)$ cells to re-establish the equilibrium ratio:

$$
\frac{d A}{d t}=-k_{1} A+k_{2} S
$$

$$
A+S=N(\text { Total number of cells })
$$

at equilibrium, $\%$ adherent cells $=A_{\text {eq }}$

$$
\begin{gathered}
\frac{d A}{d t}=0 \\
0=-\left(k_{1}+k_{2}\right) A_{\text {eq }}+k_{2} N .
\end{gathered}
$$

The above differential equation gives the general solution,

$$
A=c_{1} e^{-\left(k_{1}+k_{2}\right) t}+c_{2}
$$

with initial conditions

$t=0, A=A_{0}$, where $A_{0}$ is the initial number of cells in the adherent state)
This yields the solution

$$
A=\left(A_{0}-A_{\text {eq }}\right) e^{-\left(k_{1}+k_{2}\right) t}+A_{\text {eq }} .
$$

The best-fit solution to this simple model (Eq. 3) was compared with the experimental data in Fig. 1, and shows excellent agreement, implying that the phenotypic switch can be approximated with first-order kinetics. The constants $k_{1}$ and $k_{2}$ of the first order kinetics solution can be attributed to cell proliferation and cells switching from adherent state to the suspended state.

\section{Dynamic Switching Between the Suspended and Adherent Cells Occurs Rapidly and Reaches an Equilibrium Over Time}

The adherent and suspended cells were separated and labeled with CellTracker green and CellTracker orange dyes, respectively. To determine whether a dynamic switch between the two states maintained the existence of two subpopulations, the labeled cells were plated separately at the same seeding density. After they reached the previously observed equilibrium ratio (time to reach equilibrium ratio was determined by previous experiments to be $8 \mathrm{~h}$ ), the suspended layer from the originally suspended population (in orange) was added to the adherent layer of the originally adherent type (in green) (Fig. 2a). After 2 h, the cells in suspension were removed and analyzed using flow cytometry. The results revealed that $70 \%$ of cells in the suspended population were positive for CellTracker orange (conversely, $30 \%$ of cells were positive for CellTracker green, which were originally adherent) (Fig. 2d). We also collected the adherent cells and analyzed these cells for CellTracker green labeling. Only $85 \%$ of cells in the adherent population were positive for CellTracker green (conversely, $15 \%$ of cells were positive for CellTracker orange, which were originally suspended) (Fig. 2d). At $t=4 \mathrm{~h}$ there was an increase in the percentage of orange and green cells in the suspended and adherent populations respectively, indicating that some cells that had switched from one state to the other at $t=2 \mathrm{~h}$ switched back again. These results indicate that there is a dynamic switch between cells in the two subpopulations (Figs. 2b and 2c).

\section{Phosphorylated Kinases are Upregulated in the Suspended Population}

Relative phosphorylation levels of 12 key kinases and their protein substrates in both adherent and suspended COLO 205 cells were measured. As depicted in Fig. 3a, 9 out of 12 key kinases were found to be expressed at relatively elevated levels in the suspended COLO 205 cells compared to their adherent 


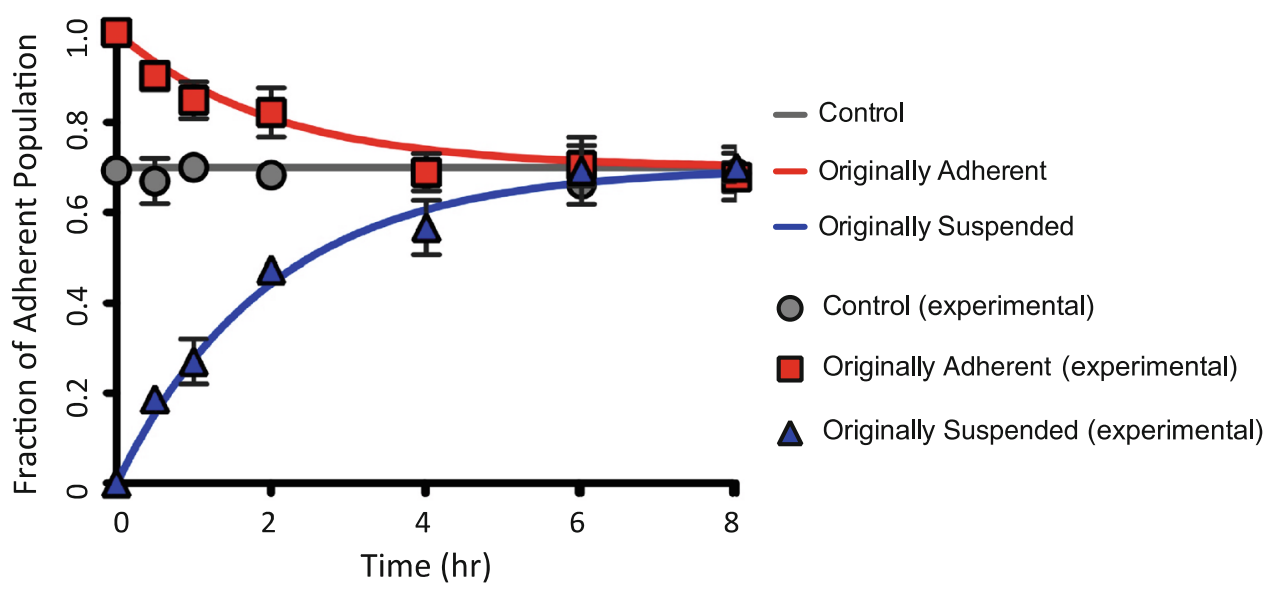

FIGURE 1. COLO 205 adherent and suspended population reformation and stabilization. Adherent and suspended cells were separated and re-plated in fresh RPMI media (data referred to as 'originally adherent' and 'originally suspended'). The originally adherent and suspended culture flasks were monitored over $8 \mathrm{~h}$ by performing cell count at $0.5,1$, and $2 \mathrm{~h}$ intervals and the fraction of adherent cells in all conditions was plotted against time. A simple ordinary differential equation (ODE) model was derived for the adherent fraction as a population balance on adherent and suspended cells. Solutions to the ODE model were plotted for the best-fit model parameters of $k=0.5 \mathrm{~h}^{-1}$ and $A_{\mathrm{eq}}=0.7$.

(a) (b)

(c)

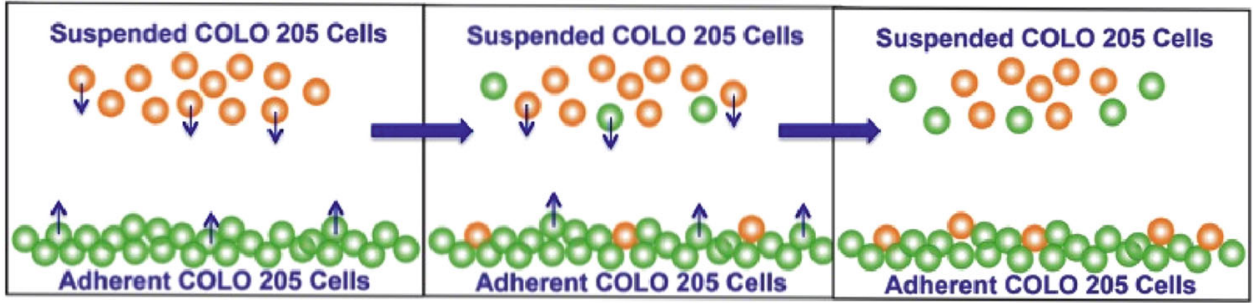

(d)

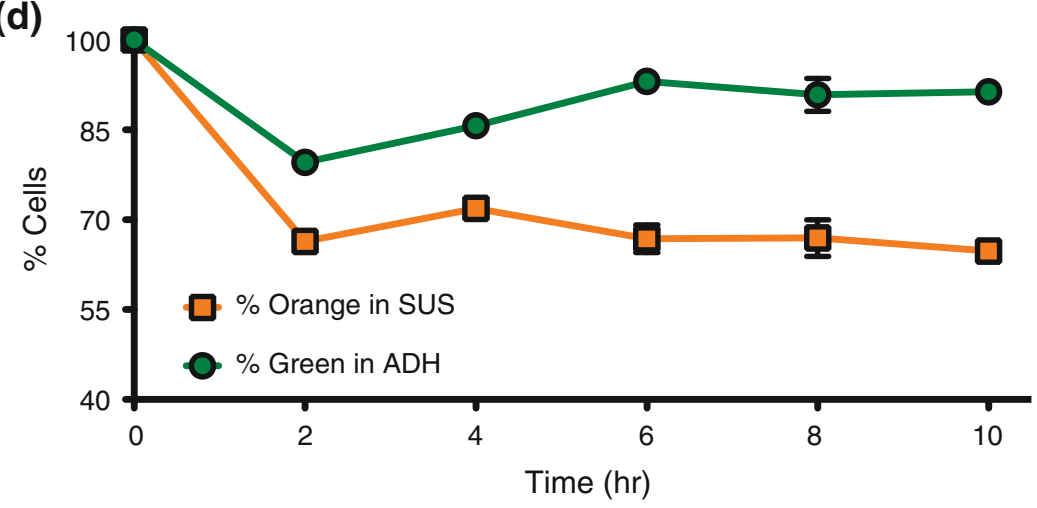

FIGURE 2. (a-c) Dynamic switch between the adherent and suspended COLO 205 populations. (d) Percentage of orange CellTracker dye labeled cells in the suspended layer (SUS) and green CellTracker dye labeled cells in the adherent layer (ADH) over $10 \mathrm{~h}$.

counterparts, among which the phosphorylation of $\beta$ catenin showed the greatest increase. The overall increase in the kinase phosphorylation activity in suspended cells can be explained by their significantly higher $\beta$-catenin gene expression (Fig. 3b). The increased phosphorylation of $\beta$-catenin protein observed in the suspended cells is also expected to reduce their binding affinity to both E-cadherin and APC, causing the suspended cells to detach and form individual cells in suspension. Increased kinase phosphorylation activity has also been recently reported to inhibit integrin mediated cell-ECM interactions. ${ }^{28}$

Suspended Cells Show Increased Expression of $\beta$-Catenin and Decreased Expression of E-cadherin

Immunoblotting results, shown in Fig. 3c, indicated that the total (surface + intracellular) $\beta$-catenin protein 


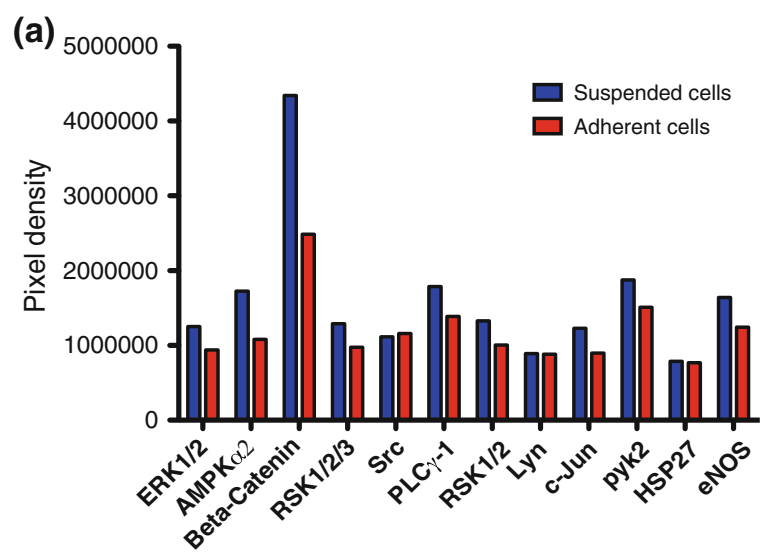

(b)

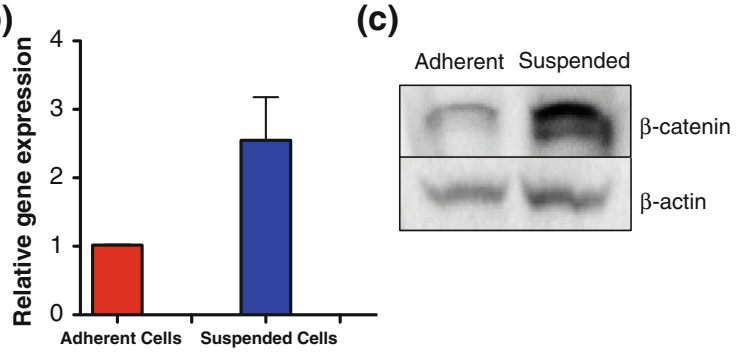

(d)

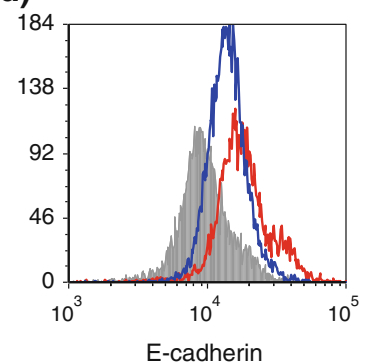

(e)

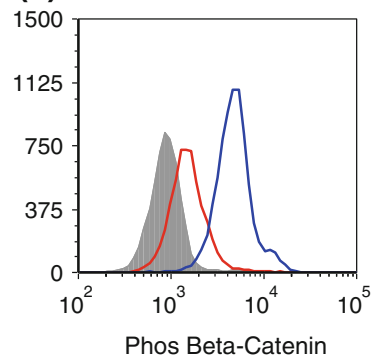

FIGURE 3. (a) Phosphorylation levels of COLO 205 adherent and suspended cells. (b) Relative $\beta$-catenin gene expression comparison between the adherent and suspended populations. Suspended cells have an average of 2.5 -fold higher $\beta$-catenin expression. (c) Immunoblotting of $\beta$-catenin protein expression in the two populations. (d) and (e) Flow cytometry plots of antiE-cadherin and anti-phosphorylated $\beta$-catenin antibody labeling. Isotypes, suspended population, and adherent population were colored in grey, blue, and red respectively.

expression was elevated in the suspended COLO 205 cells. Furthermore, flow cytometry results indicated that suspended cells express less surface E-cadherin and more cytoplasmic phosphorylated $\beta$-catenin compared to adherent cells (Figs. 3d and 3e).

\section{Manipulation of $\beta$-Catenin and E-cadherin Expression Result in Increased Number of Adherent Cells}

An average $75 \%$ decrease in $\beta$-catenin gene expression as measured by qPCR was achieved by treating COLO 205 cells with $\beta$-catenin siRNA. As a result of the significant decrease in $\beta$-catenin gene

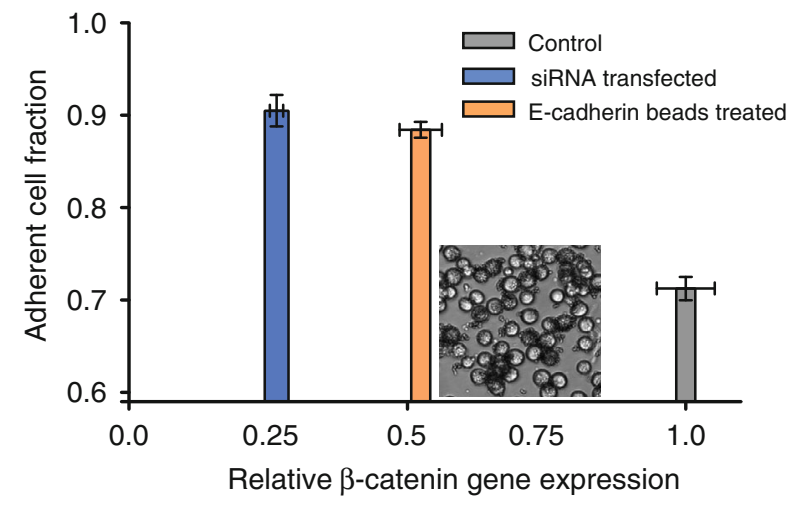

FIGURE 4. $\beta$-catenin gene expression was reduced after treating the overall COLO 205 population with siRNA. A $20 \%$ increase in the adherent cell fraction was observed. In a separate study, the overall COLO 205 cell population was incubated with E-cadherin antibody coated microspheres, which induced an increase in the adherent cell fraction and a $50 \%$ decrease in $\beta$-catenin gene expression.

expression, the equilibrium ratio between adherent and suspended cells (7:3) shifted towards the adherent state, to a measured ratio of 9:1 (Fig. 4). This increase in the COLO 205 adherent cell population suggests that $\beta$-catenin may play a role in its own gene regulation, in addition to being an important linker protein in E-cadherin mediated cell-cell interactions. It was observed that the $\beta$-catenin siRNA was not able to completely abolish $\beta$-catenin mRNA expression, leaving enough $\beta$-catenin and reduced Wnt signaling to assist the $\beta$-catenin:E-cadherin complex mediated homotypic cell aggregation. ${ }^{13,18}$ Likewise, incubating COLO 205 cells with E-cadherin antibody coated microspheres, thereby externally increasing the probability of cell-cell adhesion mediated by E-cadherin expressed on the cells, was also found to induce a significant increase in the adherent cell fraction, shifting the ratio to 9:1 (Fig. 4). Furthermore, $\beta$-catenin gene expression decreased by $45 \%$ in these artificially clustered cells compared to control.

Suspended COLO 205 Cells Express More Sialyl Lewis Acids and Show Significantly Stronger Interaction with E-selectin Coated Surfaces Under Physiological Shear Stress

To further explore the population transition in COLO 205 cells, a flow based adhesion assay was used to investigate the adhesion phenotypes of both adherent and suspended populations. As shown in Fig. 5c, suspended COLO 205 cells were found to have a rolling velocity of $1.52 \pm 0.05 \mu \mathrm{m} / \mathrm{s}$ under $1 \mathrm{dyn} / \mathrm{cm}^{2}$ shear stress, significantly slower than the adherent cells rolling at $2.10 \pm 0.04 \mu \mathrm{m} / \mathrm{s}$, indicating a more adhesive phenotype on the E-selectin coated surfaces. 
(a)

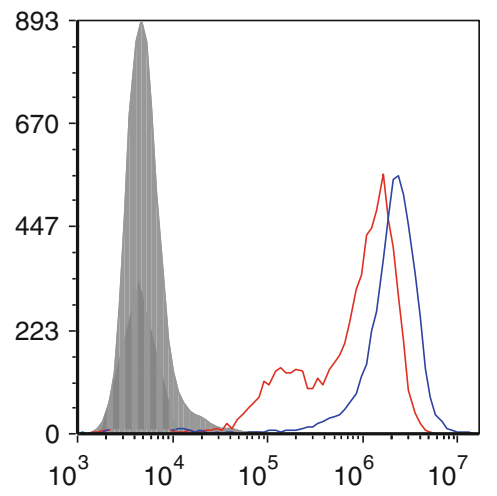

(b)

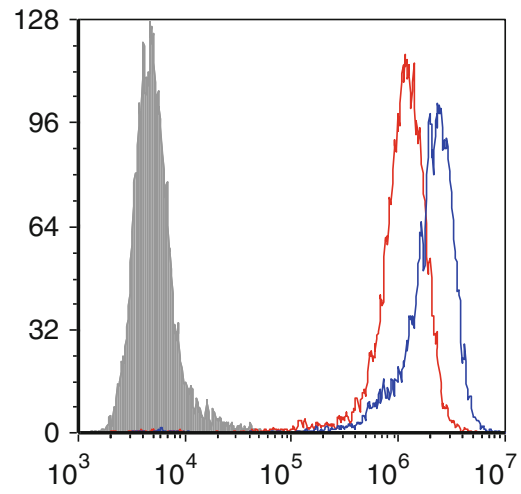

(c)

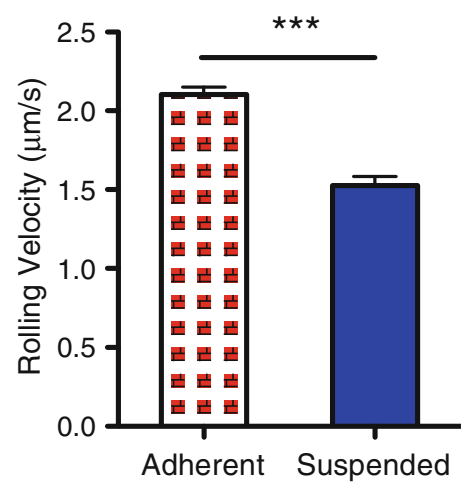

FIGURE 5. (a) and (b) Flow cytometry histogram plots of COLO 205 adherent (red) and suspended (blue) cells labeled with antisLe ${ }^{\mathrm{x}}$ and anti-sLe $\mathrm{a}^{\mathrm{a}}$ antibodies. Isotype controls are shown in grey. (c) Rolling velocity analysis of adherent (red) and suspended (blue) under $1 \mathrm{dyn} / \mathrm{cm}^{2}$ shear stress. ${ }^{* * *} p<0.0001$.

Compared to adherent cells, suspended cells were found to have elevated $\mathrm{sLe}^{\mathrm{x}}$ and $\mathrm{sLe} \mathrm{e}^{\mathrm{a}}$ expression by 60 and $80 \%$, respectively (Figs. $5 \mathrm{a}$ and $5 \mathrm{~b}$ ).

\section{Human Plasma Induces a Pro-suspension Population Shift and Increased $\beta$-Catenin Expression}

To assess whether COLO 205 cells may behave differently once they have entered the bloodstream, human plasma was isolated from healthy donors and added to the culture media. Interestingly, as shown in Figs. 6a and 6b, the majority of COLO 205 cells shifted to the suspended state, leaving significantly fewer adherent cells compared to control conditions with area of fluorescence quantified in Fig. 6c. Plasmatreated COLO 205 cells were also found to have greater expression of CD44, an E-selectin ligand, and phosphorylated $\beta$-catenin (Figs. 6d and 6e).

\section{Suspended Cells Show Increased Expression of Several EMT-Associated Genes}

The dynamic switch between the two subpopulations of COLO 205 cells, with the adherent subpopulation showing increased expression of E-cadherin, and loss of E-cadherin expression in the suspended population combined with high expression of $\beta$-catenin and stronger interaction with E-selectin, is associated with the epithelial-mesenchymal transition (EMT), which is characterized by a loss of cell adhesion and increased cell invasion in many cancers. To examine this further, we assayed the expression of several EMT-associated genes in the adherent and suspended subpopulations using qPCR. Several EMT-associated genes were found to be upregulated in the suspended cells. Notably, mRNA of fibroblast growth factor binding protein 1 (FGFBP1), matrix metalloproteinase-2 (MMP2) and secreted protein that is acidic and rich in cysteine (SPARC) were $>$ threefold higher in suspended COLO 205 cells, as shown in Fig. 7.

\section{DISCUSSION}

The heterogeneity of cancer is known to play an important role in determining the fate of cancer cells during the metastatic cascade. In this study, we characterized heterogeneity in the COLO 205 cancer cell line. This particular cell line has a subpopulation of cells that are adherent and another subpopulation of cells that are in suspended form. We showed that there is a dynamic switch between the two subpopulations of COLO 205 cancer cell lines and we further characterized the molecular heterogeneity in these two subpopulations.

The expression levels of phosphorylated kinases show that many kinases and their protein substrates are relatively more active in the suspended cell population compared to the adherent population. This is consistent with previous studies which suggest that the phosphorylation of proteins correlates with the mesenchymal phenotype of tumor cells. ${ }^{7,24}$ Two of the widely studied markers of epithelial and mesenchymal phenotypes are E-cadherin and $\beta$-catenin, respectively. ${ }^{4}$ Flow cytometry results reveal that adherent cells express more E-cadherin, while suspended cells express more phosphorylated $\beta$-catenin.

Manipulation of the $\beta$-catenin gene and surface Ecadherin expression in COLO 205 cells resulted in a shift in the population ratio with an increased number of adherent cells. Transfecting siRNA against $\beta$-catenin in COLO 205 cells shifted the adherent:suspended equilibrium ratio from $7: 3$ to $\sim 9: 1$. Similarly, by introducing E-cadherin monoclonal antibody coated 

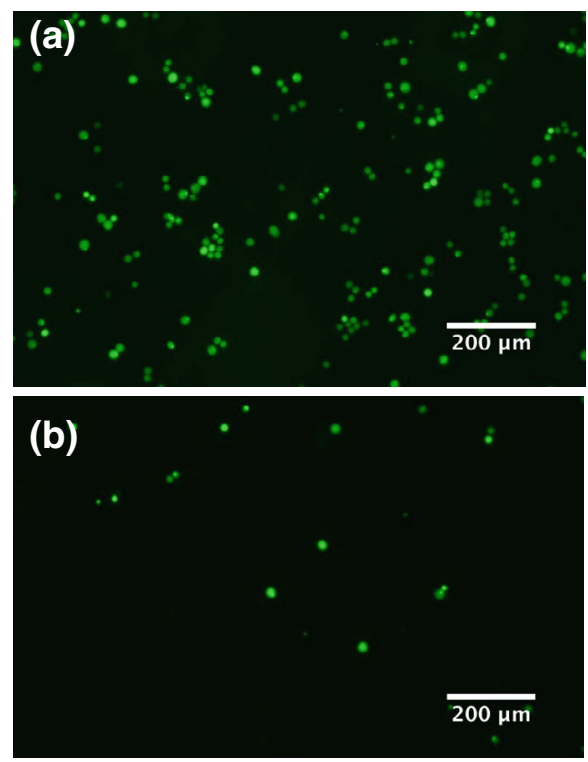

(d)

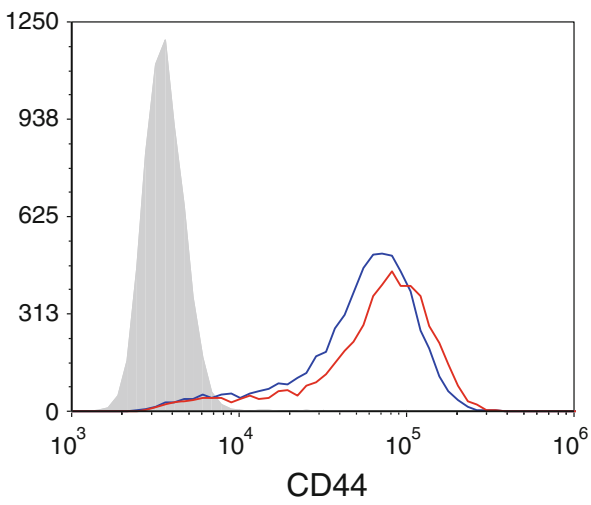

(c)

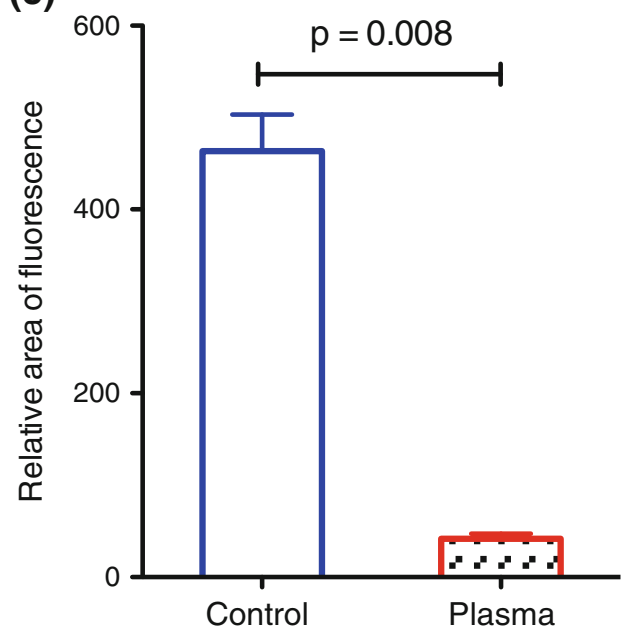

(e)

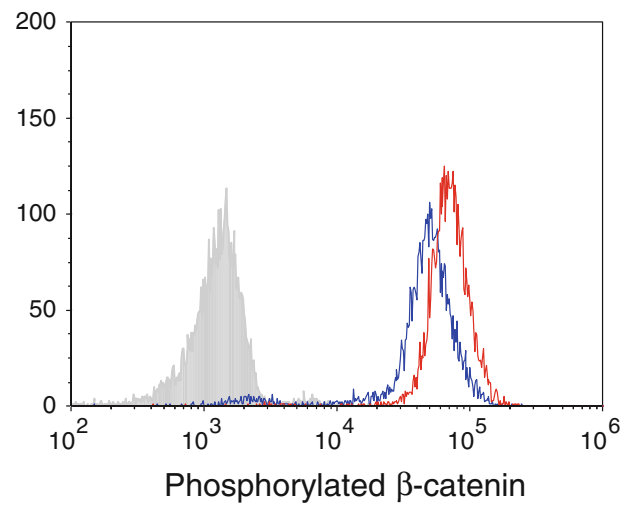

FIGURE 6. (a) and (b) Immunofluorescence images of the adherent cells after culturing in control and $50 \%$ plasma supplemented media, respectively. Cells were pre-incubated with fluorescently conjugated CellTracker dye prior to plating. (c) Quantification of the relative area of fluorescence with Image J. Two-tailed Student t-test was performed for statistical analysis ( $p=0.008)$. (d) and (e) Flow cytometry histogram plots of CD44 expression on cell surfaces and intracellular phosphorylated $\beta$-catenin expression on the control (blue) and plasma treated (red), respectively. Isotype control was also performed and shown in grey.

microbeads to the cell culture, the equilibrium ratio was also altered to $\sim 9: 1$ and $\beta$-catenin gene expression was found to decrease by $50 \%$. Taken together, these results suggest an interesting concurrent 'inside-out' and 'outside-in' regulatory system, where the decrease in $\beta$-catenin gene expression within these cells as well as the externally induced elevation of E-cadherin surface expression are both able to drive an increase in the adherent:suspended population ratio.

Interestingly, suspended COLO 205 cells were also found to roll on E-selectin at a significantly slower velocity under physiologically relevant shear stresses when compared to the adherent cell population. This suggests that if given the chance to intravasate into the blood vessel, the suspended cell population may establish stronger interactions with the inflamed endothelium. Recent studies from our group reported that blood plasma triggers an adhesive phenotypic switch of breast cancer cells on E-selectin coated surfaces under flow by upregulating E-selectin ligand and glycan expression. ${ }^{5,8}$ In this study, similarly, plasma treatment was found to elevate CD44 expression for COLO 205 cells, in addition to inducing a preferential shift from the adherent to the suspended cells, suggesting a more invasive phenotype with stronger interaction with the inflamed endothelium. Furthermore, upregulation of phosphorylated $\beta$-catenin expression was also observed. The dynamic population switch observed in this study suggests a potential mechanism, which increases the likelihood of extravasation of the circulating tumor cells from the bloodstream to develop secondary tumor sites. EMT is an 


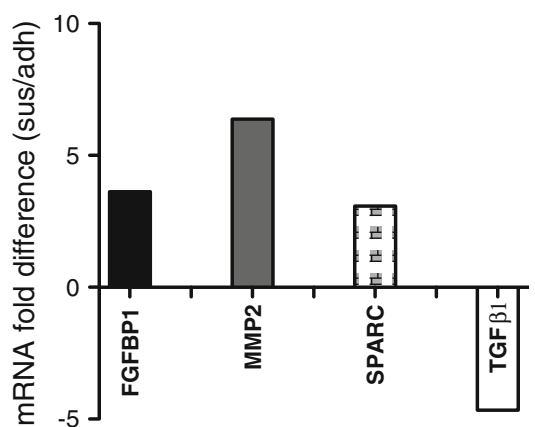

\begin{tabular}{|c|c|c|c|c|}
\hline Genes & FGFBP1 & MMP2 & SPARC & TGFB1 \\
\hline $\begin{array}{c}\text { mRNA fold difference } \\
\text { (suspended/adherent) }\end{array}$ & 3.62 & 6.38 & 3.08 & -4.66 \\
\hline
\end{tabular}

FIGURE 7. Real-time PCR of EMT-associated gene expression was performed in both suspended and adherent populations. mRNA expressions with $>3$-fold change include FGFBP1, MMP2, SPARC and TGF- $\beta 1$. The fold difference is shown in both graph and table below after normalizing to expression level in the adherent cells.

essential process in the metastatic cascade but there are theories that suggest that EMT is a continuous process that could happen while the cancer cells are in the bloodstream. EMT markers are reported to be expressed by CTCs captured from breast cancer patients indicating that factors in blood could aid in the EMT process. ${ }^{32}$ Plasma is rich in pro-inflammatory cytokines $^{8}$ that aid in the metastatic process and we found an interesting switch of COLO 205 cells preferentially to the suspended state showing increased expression of E-selectin ligands when treated with human plasma.

Several EMT-associated genes including FGFBP1, MMP2 and SPARC are upregulated in suspended COLO 205 cells. FGFBP1 and MMP2 have been previously shown to be upregulated in metastatic colorectal cancers relative to normal colon epithelia. ${ }^{23,30}$ As a mesenchymal cell marker, SPARC expression has been identified during breast cancer EMT which correlates with a basal-like phenotype. ${ }^{25}$ In contrast, transforming growth factor beta 1 (TGFB1) was downregulated in the suspended population of COLO 205 cells compared to the adherent population. As TGFB1 is considered to drive EMT through both paracrine and autocrine signaling, ${ }^{26}$ its transient upregulation in the adherent COLO 205 population may induce EMT and thus promote the transition to the suspended state. These results strongly suggest that the transition from the adherent to the suspended state creates cells that express both mesenchymal-like phenotype and genotype from a cell line of epithelial origin and may be considered EMT-like.

The suspended population expressed significantly more phosphorylated $\beta$-catenin and less E-cadherin compared to the adherent population. In epithelial cells, the intracellular domain of surface E-cadherin is associated with $\beta$-catenin. When a cell undergoes EMT there is a loss of E-cadherin expression and increased translocation of $\beta$-catenin to the nucleus. "Inside-out" manipulation via $\beta$-catenin siRNA knockdown assay to reduce the expression of cytoplasmic $\beta$-catenin, and "outside-in" manipulation via introduction of E-cadherin antibody coated microspheres to increase Ecadherin mediated cell-cell adhesion, shifted the equilibrium population ratio to $9: 1$. Therefore, we conclude that the expression of $\beta$-catenin and E-cadherin regulate the dynamic switch of COLO 205 cells as two distinct subpopulations.

In the context of metastasis, the suspended COLO 205 population represents a more invasive phenotype. Suspended cells expressed $60 \%$ more $\mathrm{sLe}^{\mathrm{x}}$ and $80 \%$ more $\mathrm{sLe}^{\mathrm{a}}$ than adherent cells, which resulted in significantly slower, rolling velocities on E-selectin coated microtubes. Moreover when cells were cultured in human plasma, the expression of phosphorylated $\beta$-catenin increased, shifting the majority of cells into the suspended population where $\mathrm{sLe}^{\mathrm{x}}$ and E-selectin ligand CD44 expression both increased as well. Upregulation of the EMT markers FGFBP1, MMP2 and SPARC within the suspended population suggests mesenchymal-like cells and therefore a much more aggressive population. Future studies could focus on the regulation of phosphorylated $\beta$-catenin or Ecadherin to control the aggressiveness of colorectal cancers to help prevent metastases.

\section{ACKNOWLEDGMENTS}

NIH Grant U54CA143876 to MRK and an NSF Graduate Research Fellowship to YG funded this work.

\section{CONFLICT OF INTEREST}

The authors have no competing financial interests to disclose.

\section{OPEN ACCESS}

This article is distributed under the terms of the Creative Commons Attribution License which permits any use, distribution, and reproduction in any medium, provided the original author(s) and the source are credited.

\section{REFERENCES}

\footnotetext{
${ }^{1}$ Agastin, S., U. B. T. Giang, Y. Geng, L. A. DeLouise, and M. R. King. Continuously perfused microbubble array for 3d tumor spheroid model. Biomicrofluidics 5(2):24110, 2011.
} 
${ }^{2}$ Baisse, B., H. Bouzourene, E. P. Saraga, F. T. Bosman, and $\mathbf{J}$. Benhattar. Intratumor genetic heterogeneity in advanced human colorectal adenocarcinoma. Int. J. Cancer 93(3):346-352, 2001.

${ }^{3}$ Borsig, L., R. Wong, R. O. Hynes, N. M. Varki, and A. Varki. Synergistic effects of $1-$ and p-selectin in facilitating tumor metastasis can involve non-mucin ligands and implicate leukocytes as enhancers of metastasis. Proc. Natl. Acad. Sci. USA 99(4):2193-2198, 2002.

${ }^{4}$ Brabletz, T., A. Jung, S. Reu, M. Porzner, F. Hlubek, L. A. Kunz-Schughart, R. Knuechel, and T. Kirchner. Variable beta-catenin expression in colorectal cancers indicates tumor progression driven by the tumor environment. Proc. Natl. Acad. Sci. USA 98(18):10356-10361, 2001.

${ }^{5}$ Chandrasekaran, S., Y. Geng, L. A. DeLouise, and M. R. King. Effect of homotypic and heterotypic interaction in $3 \mathrm{~d}$ on the e-selectin mediated adhesive properties of breast cancer cell lines. Biomaterials 33(35):9037-9048, 2012.

${ }^{6}$ Daniel, J. M., and A. B. Reynolds. Tyrosine phosphorylation and cadherin/catenin function. Bioessays 19(10):883-891, 1997.

${ }^{7}$ Deng, B., X. Yang, J. Liu, F. He, Z. Zhu, and C. Zhang. Focal adhesion kinase mediates tgf- $\beta 1$-induced renal tubular epithelial-to-mesenchymal transition in vitro. $\mathrm{Mol}$. Cell. Biochem. 340(1):21-29, 2010.

${ }^{8}$ Geng, Y., S. Chandrasekaran, J.-W. Hsu, M. Gidwani, A. D. Hughes, and M. R. King. Phenotypic switch in blood: effects of pro-inflammatory cytokines on breast cancer cell aggregation and adhesion. PLOS ONE 8(1):e54959, 2013.

${ }^{9}$ Geng, Y., J. R. Marshall, and M. R. King. Glycomechanics of the metastatic cascade: tumor cell-endothelial cell interactions in the circulation. Ann. Biomed. Eng. 40(4):790-805, 2012.

${ }^{10}$ Goetz, D. J., M. E. ElSabban, D. A. Hammer, and B. U. Pauli. Lu-ecam-1-mediated adhesion of melanoma cells to endothelium under conditions of flow. Int. J. Cancer 65(2):192-199, 1996.

${ }^{11}$ Goswami, K., H. Nandeesha, B. Koner, and D. Nandakumar. A comparative study of serum protein-bound sialic acid in benign and malignant prostatic growth: possible role of oxidative stress in sialic acid homeostasis. Prostate Cancer Prostatic Dis. 10(4):356-359, 2007.

${ }^{12}$ Hanley, W. D., M. M. Burdick, K. Konstantopoulos, and R. Sackstein. Cd44 on 1s174t colon carcinoma cells possesses e-selectin ligand activity. Cancer Res. 65(13):58125817, 2005.

${ }^{13}$ Heuberger, J., and W. Birchmeier. Interplay of cadherinmediated cell adhesion and canonical wnt signaling. Cold Spring Harb. Perspect. Biol. 2(2):a002915, 2010.

${ }^{14}$ Hughes, A. D., J. Mattison, L. T. Western, J. D. Powderly, B. T. Greene, and M. R. King. Microtube device for selectin-mediated capture of viable circulating tumor cells from blood. Clin. Chem. 58(5):846-853, 2012.

${ }^{15}$ Ilyas, M., I. P. Tomlinson, A. Rowan, M. Pignatelli, and W. F. Bodmer. Beta-catenin mutations in cell lines established from human colorectal cancers. Proc. Natl. Acad. Sci. USA 94(19):10330-10334, 1997.

${ }^{16}$ Jeanes, A., C. J. Gottardi, and A. S. Yap. Cadherins and cancer: how does cadherin dysfunction promote tumor progression? Oncogene 27(55):6920-6929, 2008.

${ }^{17} \mathrm{Li}$, J., and M. R. King. Adhesion receptors as therapeutic targets for circulating tumor cells. Frontiers Oncol. 2:79, 2012.
${ }^{18}$ Nelson, W. J., and R. Nusse. Convergence of wnt, betacatenin, and cadherin pathways. Science 303(5663):14831487, 2004.

${ }^{19}$ Nicolson, G. L. Paracrine and autocrine growth mechanisms in tumor-metastasis to specific sites with particular emphasis on brain and lung metastasis. Cancer Metastasis Rev. 12(3-4):325-343, 1993.

${ }^{20}$ Oda, T., Y. Kanai, T. Oyama, K. Yoshiura, Y. Shimoyama, W. Birchmeier, T. Sugimura, and S. Hirohashi. Ecadherin gene mutations in human gastric carcinoma cell lines. Proc. Natl. Acad. Sci. USA 91(5):1858-1862, 1994.

${ }^{21}$ Orr, F. W., H. H. Wang, R. M. Lafrenie, S. Scherbarth, and D. M. Nance. Interactions between cancer cells and the endothelium in metastasis. J. Pathol. 190(3):310-329, 2000.

${ }^{22}$ Oyama, T., Y. Kanai, A. Ochiai, S. Akimoto, T. Oda, K. Yanagihara, A. Nagafuchi, S. Tsukita, S. Shibamoto, F. Ito, et al. A truncated beta-catenin disrupts the interaction between e-cadherin and alpha-catenin: a cause of loss of intercellular adhesiveness in human cancer cell lines. Cancer Res. 54(23):6282-6287, 1994.

${ }^{23}$ Papadopoulou, S., A. Scorilas, N. Arnogianaki, B. Papapanayiotou, A. Tzimogiani, N. Agnantis, and M. Talieri. Expression of gelatinase-a (MMP-2) in human colon cancer and normal colon mucosa. Tumour Biol. 22(6):383-389, 2001.

${ }^{24}$ Santibanez, J. F., J. Kocic, A. Fabra, A. Cano, and M. Quintanilla. Rac1 modulates tgf-beta 1-mediated epithelial cell plasticity and MMP9 production in transformed keratinocytes. Febs Lett. 584(11):2305-2310, 2010.

${ }^{25}$ Sarrio, D., S. M. Rodriguez-Pinilla, D. Hardisson, A. Cano, G. Moreno-Bueno, and J. Palacios. Epithelial-mesenchymal transition in breast cancer relates to the basallike phenotype. Cancer Res. 68(4):989-997, 2008.

${ }^{26}$ Scheel, C., E. N. Eaton, S. H. Li, C. L. Chaffer, F. Reinhardt, K. J. Kah, G. Bell, W. Guo, J. Rubin, A. L. Richardson, and R. A. Weinberg. Paracrine and autocrine signals induce and maintain mesenchymal and stem cell states in the breast. Cell 145(6):926-940, 2011.

${ }^{27}$ Semple, T. U., L. A. Quinn, L. K. Woods, and G. E. Moore. Tumor and lymphoid cell lines from a patient with carcinoma of the colon for a cytotoxicity model. Cancer Res. 38(5):1345-1355, 1978.

${ }^{28}$ Spassov, D. S., C. H. Wong, N. Sergina, D. Ahuja, M. Fried, D. Sheppard, and M. M. Moasser. Phosphorylation of trask by src kinases inhibits integrin clustering and functions in exclusion with focal adhesion signaling. Mol. Cell. Biol. 31(4):766-782, 2011.

${ }^{29}$ Takeichi, M. Cadherin cell adhesion receptors as a morphogenetic regulator. Science 251(5000):1451-1455, 1991.

${ }^{30}$ Tassi, E., R. T. Henke, E. T. Bowden, M. R. Swift, D. P. Kodack, A. H. Kuo, A. Maitra, and A. Wellstein. Expression of a fibroblast growth factor-binding protein during the development of adenocarcinoma of the pancreas and colon. Cancer Res. 66(2):1191-1198, 2006.

${ }^{31}$ Weigelt, B., J. L. Peterse, and L. J. van't Veer. Breast cancer metastasis: markers and models. Nat. Rev. Cancer 5(8):591-602, 2005.

${ }^{32}$ Yu, M., A. Bardia, B. S. Wittner, S. L. Stott, M. E. Smas, D. T. Ting, S. J. Isakoff, J. C. Ciciliano, M. N. Wells, A. M. Shah, K. F. Concannon, M. C. Donaldson, L. V. Sequist, E. Brachtel, D. Sgroi, J. Baselga, S. Ramaswamy, M. Toner, D. A. Haber, and S. Maheswaran. Circulating breast tumor cells exhibit dynamic changes in epithelial and mesenchymal composition. Science 339:580-584, 2013. 